\title{
The Effect of Choral Music on Emotions, Immune Parameters and Lung Function during Physiotherapy Treatment of Pneumonia and Bronchitis
}

\begin{abstract}
Introduction: Music, processed by the brain, has a strong impact on the emotions and health. The Magnificat in D major of JS Bach communicates not only a positive emotion of happiness but also motivational behaviour. Infectious lung conditions are often associated with negative emotions which develop due to physiological changes. The hormonal action of the hypothalamuspituitary-adrenal axes (HPA) could be negatively affected by emotions of anger and depression. This will result in a disturbance of the mind-body interaction. Music therefore can exert a powerful influence on therapeutic benefits

Le Roux FH¹, Bouic PJD²; Bester $\mathbf{R}^{3}$

1 Private Practice, Fish Hoek.

2 Department Medical Microbiology,

University of Stellenbosch, South Africa.

3 Department of Physiotherapy, University

of Stellenbosch, South Africa. by changing the psychological status and the immune endocrine functions.

The purpose of this study was to determine the effect of music, during respiratory physiotherapy treatment on a) the emotional status, b) neuroendocrine responses, c) immune functions and d) lung functions of subjects with infected lung conditions.

Method and Materials: Forty subjects attending physiotherapy treatment was selected according to set criteria and randomly assigned to an experimental and control group. The parameters (Profile Of Mood State [POMS]; CD4: CD8 cell ratios; Cortisol; the Cortisol: DHEA ratio; PF; FEVI; FVC and FEVI/FVC \%) were measured on day 1 before the treatment and on day 3 after the treatment. Data were analysed with Statistica (Statsoft) using the Repeated ANOVA tests.

Results: Results indicated that the intervention of music had a positive effect on the immunological parameter (CD4+:CD8+ cell ratios) and on the cortisol and cortisol:DHEA ratio levels. At the same time the psychological status as measured by Profile of Mood States (POMS scale) improved with a significant improvement in the lung functions. Conclusion: The research provided sufficient scientific evidence that music affects both the biomedical and psychosomatic aspects of infectious lung conditions.
\end{abstract}

KEYWORDS: PHYSIOTHERAPY; MUSIC; EMOTIONS; IMMUNE PARAMETERS; ENDOCRINE HORMONES.

\section{INTRODUCTION}

Substantial research has led to a revolutionary transformation in the way the relationship is viewed between the mind and health and the mind and illness (Grol, 2001; Shine, 2002). It is now clear that negative emotions, will be primarily physiologically induced with infectious conditions that can lead to alterations in neurohormonal activity (Linn et al, 1984, and Cohen, 2000).

\section{CORRESPONDENCE TO:}

FH le Roux

Hove to Medical Centre

3rd Avenue,

Fish Hoek 7975

Tel/Fax: (021) 782-3614

Email: adagio.frances@absamail.co.za
This implies that mood disturbances seen during inflammatory and infectious conditions may partially result from the production of pro-inflammatory cytokines (Viljoen et al, 2003). Negative emotions, such as depression, anxiety and anger could directly influence the cells of the immune systems and hormonal levels (McCraty, 1999; Kiecolt-Glaser et al, 2002). Cortisol increases with stress (Kiecolt-Glaser et al, 1984), and decreases as a result of a positive emotion (Berk et al, 1989; Gunner, 1991). Suppressed negative emotions may block network pathways and stop the flow of biochemicals that run both our biology and our behaviour and are linked to the progression of an illness (Pert, 1997).

The negative influence of psychological variables on the immune system suggests the possibility that it may also be manipulated in a positive way. Music, which is an emotional communicator that could offer a positive emotional experience, has the ability to bypass the conscious mind and directly access the subconscious mind (Legge, 1999). Music is firstly processed by the brain (Thaut, 2003), which is also the body's first line of defence against illness (Azar, 2001).

Research shows that music intervention is able to change mood, reduce anger/hostility and disorders, such as fear, depression and stress, and improve energy levels (Magee and Davidson, 2002; Spintge and Droh, 1992; Brennan and Charnetski, 2000; Hargreaves and North 1999). Other studies have demonstrated the immuno-enhancement of 
cell-mediated (Rider and Achterberg, 1990) and humoral immunity (Rider and Weldin, 1990) via the use of immune system imagery accompanied by background music, and that, combining music with other psychosomatic interventions indicates a decrease of cortisol levels and an increase of interleukin-1 (Bartlett, Kaufman and Smeltekop, 1993). A study by Hirokawo and Ohira (2003) reported that music altered the mood of stressed subjects, but with no changes of the immune parameters.

The aim of respiratory physiotherapy treatment as stated by Bott and Moran (1995) is - to reduce fear and anxiety, breathlessness; to improve the efficiency of ventilation; mobilise and aid expectoration of secretions; management of pathology; as well as knowledge to improve exercise tolerance. Batt (2000) stated that reduction of fear and anxiety may be achieved with the normal physiotherapeutic skills of compassion and caring. The acoustic stimuli has been used successfully in physiotherapy to reduce pain (Le Roux, 1999) to create a positive experience between the physiotherapist and paediatric patients with cystic fibrosis (Grasso et al, 1999) and to improve healthy interrelationship between physiotherapist and patient (Booker et al 1985).

The purpose of this study was to investigate the effect of music on selective parameters, while the patients were receiving physiotherapeutic treatment for pneumonia and bronchitis. The hypotheses for this study were a) music would effect the emotions, immune and endocrine systems, b) there would be a relation between the psychosomatic and biomedical changes and c) there would be a significantly positive change of emotions in the experimental group in comparison with the control group.

\section{METHODS}

Forty subjects $(\mathrm{n}=40)$ with pneumonia or acute bronchitis, diagnosed by general practitioners, were randomly selected to participate in this study. Randomisation was carried by means of sealed envelopes: each patient was requested to choose an envelope and upon unsealing, was assigned to the group as indicated. All the subjects were recruited from a private physiotherapy practice (Fish Hoek, South Africa) after referral from a general practitioner for treatment. The research was approved by the Human Research Committee of Stellenbosch University. The subjects falling within the age range of 35-75 years signed a consent form to indicate their willingness to participate in the study. Each patient was coded and all samples were blinded to the laboratory personnel conducting the assays.

The following subjects were excluded from the study:

1. HIV positive subjects.

2. All subjects who presented with secondary lung pathology, as diagnosed by general practitioners.

3. Subjects using immune modulated drugs like Moducare or cortisone.

\section{PROCEDURE}

Subjects had objective and subjective evaluation of the respiratory system on the first day. The information obtained was reviewed in order to select participants according to the inclusion criteria. The subjects were asked to complete the Profile of Mood States (POMS-scale). After completion approximately $15 \mathrm{cc}$ blood was drawn by a registered nurse appointed by the local pathological services. This blood sample was transported to the laboratory at Tygerberg Hospital for analysis under supervision of a microbiologist. The following tests were conducted: Cortisol levels (RIA, Amerhsam), the Cortisol: DHEA ratio and CD4: CD8 cell ratios (by flow cytometry).

For the lung function determination, the subjects were asked to undertake forced expiration into a calibrated ventilometer while standing. The subjects received respiratory physiotherapy treatment which included nebulising with atrovent/saline solution, percussions, breathing exercises and active coughing.

The music intervention for the subjects who were randomly assigned to the experimental group consisted of the volunteers listening to the Magnificat in D major BWV243 of J.S. Bach for the duration of treatment, which was restricted to 30 minutes. The control group received only the standard physiotherapy treatment for the same duration of time. The treatment was repeated for three consecutive days and at the end of the third treatment, the measuring procedure was repeated.

\section{Instruments and outcome measures}

The POMS scale consists of 65 items in a self-report inventory of adjectives that describes different positive and negative emotional states. Subjects rate each item on a 5-point scale from 0 (not at all) to 4 (extremely). Scoring potentially results in scores for each of six discrete affective states: Tension/Anxiety; Depression/Dejection; Depression/Dejection; Anger/Hostility; Vigour/Activity; Fatigue/Inertia and Confusion/Bewilderment. The POMS was selected because it has been standardised for a non-psychiatric population (McNair et al, 1981).

Whole blood samples (EDTAanti-coagulated) were processed within 6 hours of blood drawn. Briefly, 100uL blood was mixed with an $20 \mathrm{uL}$ aliquot of a mixture of monoclonal antibodies purchased from Becton Dickson (SA Scientific, Cape Town). The tubes containing the blood and monoclonal antibody mixture were incubated at room temperature for 15 minutes in the dark and thereafter $450 \mathrm{uL}$ of a lysing buffer (FACS lysing buffer, Becton Dickinson, SA Scientific, Cape Town) was added to each tube. The tubes were incubated in the dark for a further 10 minutes at room temperature and subsequently analysed on a flow cytometer (FACS Calibur, Becton Dickson, SA Scientific, Cape Town).

The adrenal cortisol and dihydroepiandrosterone sulphate (DHEAs) were measured in clotted blood samples collected at the same time as those above. The samples were centrifuged and the serum stored at $-20^{\circ} \mathrm{C}$ until assayed. The two hormones were assayed with radio-immune assays (Amersham, Cape Town). The results were expressed as individual hormones (DHEAs in umol/L and cortisol in $\mathrm{nmol} / \mathrm{L}$ or as the ratio between the cortisol:DHEAs levels in order to normalize the individual variations. All assays were conducted on the frozen sera in order to minimise batch to batch variation in the measurements.

The measurement of the lung functions were performed by a calibrated ventilometer (Clement Clark; Kat no 3108001 Reg Des no 1060400 Patent 
GB 2238130 UK). The peak flow (PF), forced expiratory volume in one second (FEV1) and forced vital capacity (FVC) and the $\%$ of FEV1 / FVC were measured by a registered physiotherapist, the highest values were taken from three satisfactory attempts.

\section{RESULTS}

Comparison of the parameters of the two groups at baseline indicated that the groups were balanced and that no statistical differences existed prior to the intervention and assays for the diverse biological markers. Nine (9) men and 31 females were included in the study. (See Table 1, Demographics of groups at baseline).

\section{Hormonal and immune changes}

Our results show that the experimental group had reduced their serum cortisol levels on the third day, (368 vs. 336) whereas the same parameter had increased in the control group during the same period (409 vs. 447). The difference between the experimental and control group was statistically significant $(\mathrm{p}<0.001)$. Cortisol is known to have immune suppressive activity on the functioning of the white blood cells and since these results indicate that the intervention with music lead to a drop of this hormone in the experimental group, it implies that after music intervention and physiotherapy treatment, this group would have improved more dramatically when compared to the control group.

Other parameters which substantiate the above observation include the results of the cortisol: DHEA ratio: in the experimental group, this ratio was significantly reduced by day 3 whereas in the control group, this ratio had increased. The difference was also statistically significant $(\mathrm{p}=0.04)$. Again, the increase in the Cortisol: DHEA ratio (as observed in the control group) implies either an increase in the Cortisol or a decrease in the DHEA level or both. This indirectly indicates a greater immune suppressed state of the patient since DHEA counter-regulates the immune suppressive activity of Cortisol.

Furthermore, the immune parameter of CD4: CD8 cell ratios reveal a significant difference among the experimental group on the third treatment day
$(2.07+/-0.95$ vs. $2.25+/-1.17, \mathrm{p}=0.045)$ whereas the ratio in the control group had declined over the same period of time 2.18 +/- 1.46 vs. 2.06 +/- 1.46. Again, the difference between groups was statistically significant ( $\mathrm{p}<0.001$ ). Once again, an increase in the ratio between the CD4 and CD8 cells implies a less suppressed state and this is clinical relevant to the outcome of an infective state.

\section{Emotions}

(See Figure 1).

TABLE 1: DEMOGRAPHICS OF GROUPS AT BASELINE.

Table 1.1: Demographics of subjects that participate in study group.

\begin{tabular}{|l|c|c|c|c|}
\hline & Male & Female & Ave Age & Age spectrum \\
\hline Experimental & 4 & 16 & 60 & $40-70$ \\
\hline Control & 5 & 15 & 65 & $43-75$ \\
\hline
\end{tabular}

Table 1.2: Comparison of parameters between experimental and control groups day one before intervention.

\begin{tabular}{|l|l|l|l|}
\hline $\begin{array}{l}\text { Parameter } \\
\text { Day } 1\end{array}$ & $\begin{array}{l}\text { Experimental Gr } \\
\text { Day } 1\end{array}$ & Control Group & Significant \\
\hline Cortisol & $368.1+/-134.17$ & $409.55+/-156.3$ & NS \\
\hline Cort: DHEA ratio & $295.17+/-195.75$ & $356.26+/-225.51$ & NS \\
\hline Average POMS & $99.30+/-46.98$ & $93.75+/-33.93$ & NS \\
\hline FVC & $2.15+/-0.79$ & $2.22+/-1.05$ & NS \\
\hline FEV1 & $1.60+/-0.84$ & $1.70+/-0.87$ & NS \\
\hline FVC/FEV1 & $0.73+/-0.25$ & $0.74+/-0.20$ & NS \\
\hline PF & $316+/-91.79$ & $303.16+/-146.12$ & NS \\
\hline CD4+:CD8+ ratio & $2.07+/-0.95$ & $2.18+/-1.46$ & NS \\
\hline
\end{tabular}

NS = not significant

Figure 1: The parameters of the POMS subscale comparing the experimental and control group.

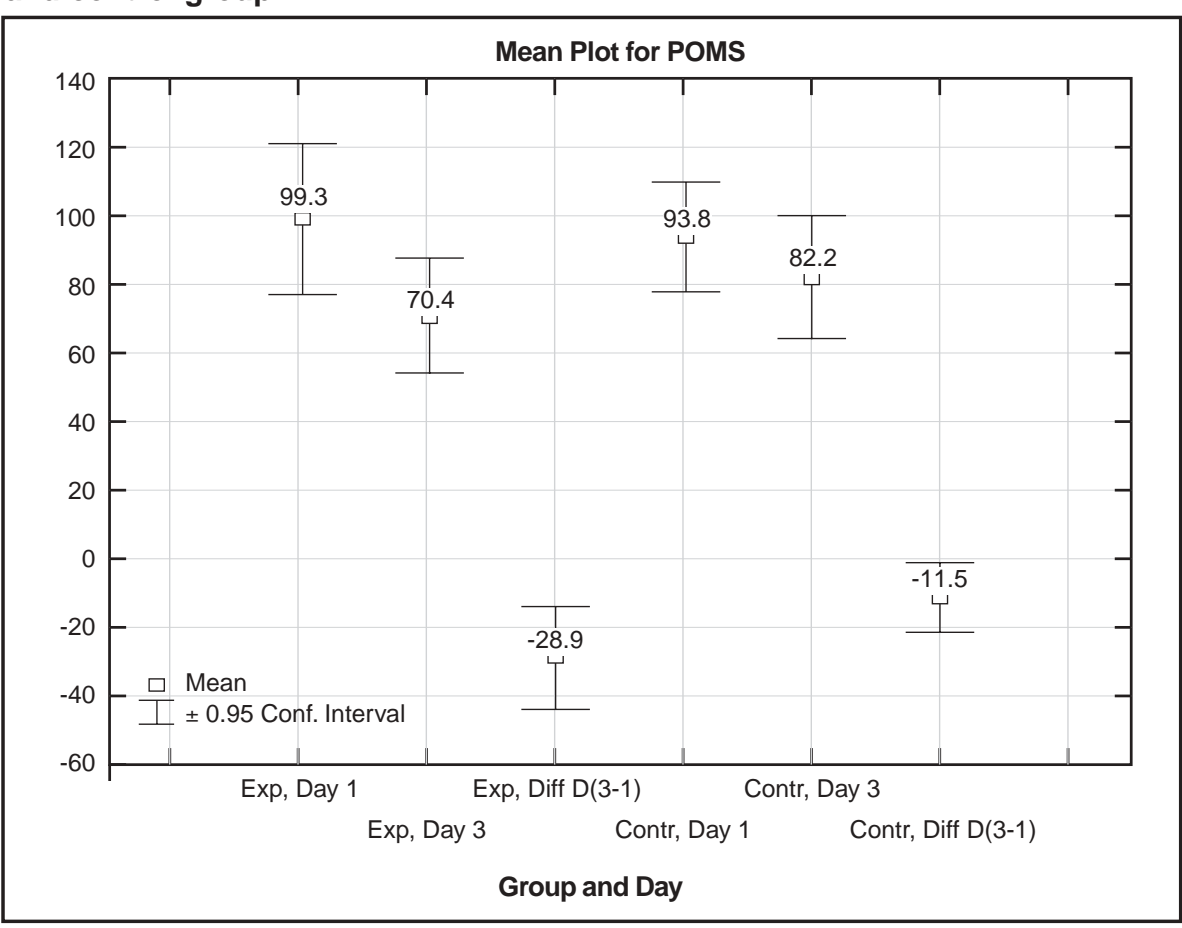


The subscale of depression and anger showed no significant changes in the control group, but significant changes in the experimental group regarding depression $(\mathrm{p}=0.001)$ and anger $(\mathrm{p}=0.007)$. In Figure 1 the composite parameters of the POMS scale are represented: it can be seen that although both groups showed an improvement in the general POMS composite value, the change was greater for the experimental group when compared to that of the control group.

The experimental group showed the most dramatic changes in the psychological parameters measured individually (Dep, Ten, etc) as well as collectively (total score) expressed as the composite POMS score. This is evident when one compares the parameters for the control group (Table 2) to those measured in the experimental group (Table 3 ).

\section{Lung Functions}

The ventilometer parameters measured showed the most dramatic positive changes in the experimental group. Indeed, as shown in Table 4, the peak flow of these patients reveal a dramatic increase of 70 litres $(316+/-91.8$ day 1 vs. $382.4+/-68.3$ day 3 ; $p, 0.0001)$. In the control group, this change was less dramatic although the patients did show an improvement (303 +/- 146.1 day 1 vs. $308.6+/-154.4$ day $3, \mathrm{NS})$. The change in this parameter between groups was statistically significant $(\mathrm{p}<0006)$

\section{DISCUSSION}

During an infective illness, negative emotions are induced, which could be ascribed both to physiological (due to biochemical changes) and psychological changes (Knapp, 1992; De Rijk et al, 1997).

The tension/anxiety subscale of the POMS scale in both the experimental and control group were significantly improved. However, when one compares the differences between groups, it appears that the intervention with music adds substantial value to physiotherapy: the control group registered no significant changes in the subscale of anger/hostility and depression while the experimental group indicated significant statistically differences in both the anger/hostility subscale $(\mathrm{p}=0.007)$ and depression subscale $(p=0.001)$ despite these parameters being similar (not statistically significant) at baseline. Depression has often been interpreted as suppressed anger (Pert, 1997). It is feasible that the negative suppressed emotion of the control group also resulted into a higher level of cortisol by day 3, whereas the experimental group $(\mathrm{p}=0.009)$ had significantly lowered their cortisol level. Although short-term decreases in cortisol following periods

Table 2: Changes in various sub-parameters of the POMS scale in the control group over a period of 3 days (baseline versus day 3 ).

\begin{tabular}{|l|l|l|l|}
\hline Sub-Parameter & $\begin{array}{l}\text { Day 1 } \\
\text { Baseline }\end{array}$ & $\begin{array}{l}\text { Day 3 } \\
\text { After intervention }\end{array}$ & $\begin{array}{l}\text { Significance } \\
(p=0.05)\end{array}$ \\
\hline TEN & $20.55+/-7.51$ & $17.4+/-9.01$ & 0.04 \\
\hline DEP & $23.25+/-9.57$ & $20.45+/-11.36$ & NS \\
\hline ANG & $18.3+/-12.05$ & $16.2+/-11.20$ & NS \\
\hline CON & $15.1+/-5.86$ & $13.4+/-6.13$ & 0.03 \\
\hline FAT & $17.15+/-8.51$ & $15+/-6.81$ & 0.04 \\
\hline VIG & $-19.9+/-8.26$ & $-21.6+/-7.71$ & 0.03 \\
\hline Total POMS scale & $93.75+/-33.93$ & $82.20+/-38.14$ & 0.03 \\
\hline
\end{tabular}

$\mathrm{NS}=$ not significant

Table 3: Changes in various sub-parameters of the POMS scale in the experimental group over a period of 3 days (baseline versus day 3 ).

\begin{tabular}{|l|l|l|l|}
\hline Sub-Parameter & $\begin{array}{l}\text { Day 1 } \\
\text { Baseline }\end{array}$ & $\begin{array}{l}\text { Day 3 } \\
\text { After intervention }\end{array}$ & $\begin{array}{l}\text { Significance } \\
(p=0,05)\end{array}$ \\
\hline TEN & $21.45+/-8.86$ & $15.3+/-7.95$ & 0.0004 \\
\hline DEP & $25.76+/-15.0$ & $17.5+/-9.60$ & 0.001 \\
\hline ANG & $16.9+/-11.63$ & $11.75+/-6.36$ & 0.007 \\
\hline CON & $15.6+/-7.7$ & $12.7+/-7.07$ & 0.006 \\
\hline FAT & $19.65+/-9.70$ & $13.25+/-8.58$ & 0.00001 \\
\hline VIG & $-17.3+/-7.02$ & $-21.15+/-5.49$ & 0.0002 \\
\hline Total POMS scale & $99.30+/-46.98$ & $70.35+/-36.19$ & 0.0003 \\
\hline
\end{tabular}

NS = not significant

Table 4: Changes in the ventilometric measurement in the experimental group over the 3 day period of study.

\begin{tabular}{|l|l|l|l|}
\hline Parameter & $\begin{array}{l}\text { Day 1 } \\
\text { Baseline }\end{array}$ & $\begin{array}{l}\text { Day 3 } \\
\text { After intervention }\end{array}$ & $\begin{array}{l}\text { Significance } \\
(\mathrm{p}=0.05)\end{array}$ \\
\hline FVC & $2.15+/-0.79$ & $2.22+/-0.75$ & NS \\
\hline FEV1 & $1.60+/-0.84$ & $1.89+/-0.68$ & NS \\
\hline FVC/FEV1 & $0.73+/-0.25$ & $0.81+/-0.19$ & NS \\
\hline PF & $316+/-91.79$ & $382.25+/-68.33$ & 0.00001 \\
\hline
\end{tabular}

NS = not significant of listening to music have been observed in healthy individuals (Bartlett, Kaufman cortisol increase experienced by patients undergoing surgery with epidural anaeshas as yet been undertaken on infected diseases with related negative emotions. Previous studies also indicate a relationship between a decrease of tension 
(relaxation) and a decrease of cortisol among hypertension and diabetic persons (Surwit and Feinglos, 1984). A previous study by McCraty (1999) reveals a relation between increased anger and cortisol: DHEAs ratio. The latter correlates with this researcher's findings relating to the significant decrease of the subscale anger and the cortisol: DHEA's ratio $(p=0.04)$. These findings indicate that the hormonal action of the hypothalamus-pituitaryadrenal axis (HPA) could be negatively affected by suppressed emotion.

The hypothalamus, is the area involved in the processing of music and emotions (Roederer, 1985). The music stimuli would first reach the thalamus, which is connected to the amygdala, the process area of negative emotions. If all negative emotions are not strongly expressed, these will create a blockage of the neuropeptides flow. Previous research indicates that the immune system would improve upon an increase of CD4 cells if negative emotions are expressed (Petrie et al, 1998). The amygdala also links with the nucleus accumbens, the centre of positive emotions and it would develop an inhibitory effect on the amygdala (Le Doux, 2000). This again would affect the HPA-axis and lower the cortisol levels and improve the immune system (Taylor, 1999). In this study the experimental group on the third treatment day showed a significant improvement of the CD4 : CD8 cell ratio $(p=0.045)$ which indicates an improved immune system.

The physiological results also indicated a significant improvement of the peak flow measurement of the experimental group $(p=0.04)$. When the experimental and control group were compared, the experimental group indicated again a statistically significant difference $(p=0.001)$. Again, statistical evaluation of the groups at baseline indicated no differences in the groups therefore this change cannot be attributed to the baseline differences. Peak flow changes have been measured during psychosocial intervention of laughter and guided self-management of asthma patients, but no psychological intervention was reported during any other physiotherapy treatment (Wensley and Silverman, 2004; Liangas et al, 2003).
This indicates that our emotions, immune and nervous system conceptually form an indivisible whole, and this also demonstrates communication between the body, mind and emotions. The findings of the research provide sufficient substantiation to conclude that immune modulation through specific functional music is able to provide a positive emotional action and better lung function. The research data confirm the healing value of music within both the psychosocial and biomedical aspects of the infectious lung conditions.

\section{REFERENCES}

Azar B 2001 A new take on psychoneuroimmunology. Monitor on Psychology December 32(11):34-36.

Bartlett D, Kaufman D, Smeltekop R 1993 The effects of music listening and perceived sensory experiences on the immune system as measured by interleukin-1 and cortisol. Journal of Music Therapy 7:10-16.

Batt J 2000 Respiratory care. Physiotherapy Jan 86(1):2-4.

Berk LS, Tan SA, Fry WF, Napier BJ, Lee JW, Hubbard RW, Lewis JE, mirthful laughter. American Journal of Medical Science 298 Eby WC 1989 Neuroendocrine and stress hormone changes during:390-396.

Booker H, Harries D, Rehahn M, Collins J 1985 Progressive exercise training: subjective and objective changes. Physiotherapy Practice 1:31-36.

Bott J, Moran F 1995 Physiotherapy and NIPPV. In: Simonds A (ed) Non-invasive Respiratory Support. Chapman and Hall, London.

Brennan FN, Charnetski CJ 2000 Stress and immune system function in a newspaper newsroom. Psychological Reports 37:218-222.

Cohen HJ 2000 Editorial: In search of the underlying mechanisms of frailty. Journals of Gerontology: Biological Sciences and Medical Sciences, ssA, M706-M708.

De Rijk R, Michelson D, Karp B, Petrides J, Galliven E, Deuster P, Paciotti G, Gold PW, Sternberg EM 1997 Exercise and circadian rhythm-induced variations in plasma cortisol differentially regulate interleukin-1b, (IL-1b), IL-6, and tumor necrosis factor- a (TNFa) production in humans: high sensitivity of TNF-a and resistance of IL-6. The Journal of Clinical Endocrinology and Metabolism 82(7):2182-91.

Grasso MC, Allison DJ, Button BM, Sawyer SM 1999 Music and Physiotherapy: Evaluation of a program developed for caregivers of infants and toddlers with cystic fibrosis. In: Pratt RR, Grocke DE (eds) Music Medicine 3. University of Melbourne.
Grol R 2001 Improving the quality of medical care JAMA 286:2578-2601.

Gunner MR 1991 The Psychobiology of stress in early development: reactivity and regulation. In: Proceedings of the International Society for the Study of Behavioral Development, Minneapolis MN.

Hargreaves DJ, North AC 1999 The function of music in everyday life: redefining the social in music psychology. Psychology of Music 27(1):84-95.

Hirokawa E, Ohira H 2003 The effects of music listening after a stressful task on immune functions, neuroendocrine responses and emotional states in college students. Journal of Music Therapy XL(3):189-211.

Kiecolt-Glaser JK, McGuire L, Robles TF, Glaser R 2002 Emotions, morbidity and mortality: New perspectives from psychoneuroimmunology. Annual Review of Psychology: 53:83-107.

Kiecolt-Glaser JK, Ricker D, George J, Messick G, Speicher CE, Garner W, Glaser R 1984 Urinary cortisol levels, cellular immunocompetency and loneliness in psychiatric inpatients. Psychosomatic Medicine 46:15-23.

Knapp P, Levy E, Giorgi R, Black P, Fox B, Heeren T 1992 Short-term immunological effects of induced emotion. Psychosomatic Medicine 54:133-149.

Le Doux JE 2000 Emotion circuits in the brain. Annual Review of Neuroscience. 23:155-184.

Le Roux FH 1999 Die effek van Largo-tempo musiek op pyn tydens fisioterapeutiese behandeling van werwelkolom patologie. MA thesis, University of Western Cape.

Legge MF 1999 Music for health: The five elements tonal system. In: IEEE Engineering in Medicine and Biology March/April 80-88.

Liangas G, Morton JE, Henry RL 2003 Mirth-triggered asthma: Is laughter really the best medicine? Pediatric Pulmonology Aug 36(2):107-12.

Linn MV, Linn BS, Jense J 1984 Stressful events dysphonic mood and immune responsiveness. Psychological Reports 54:219-222.

Magee WL, Davidson JW 2002 The effect of music therapy on mood states in neurological patients: A Pilot Study. Journal of Music Therapy XXXIX (1):20-29.

McCraty R 1999 Music and the immune system. Proceedings of the Tenth International.

McNair DM, Lorr M, Droppelman LF 1971 Profile of mood states. Educational and Industrial Testing Service, San Diego.

Pert CB 1997 Molecules of emotion, pp 181191. Simon and Schuster, London.

Petrie KJ, Booth RJ, Pennebaker JW 1998 The immunological effects of thought suppression. Journal of Personal Social Psychology Nov 75(5):1264-72. 
Rider MS, Achterberg J, Lawlis GF, Goven A, Toledo R, Butler JR 1990 Effect of immune system imagery on secretory $\operatorname{IgA}$. Biofeedback Self Regulation, 15:317-333.

Rider MS, Weldin C 1990 Imagery, improvisation and immunity. Arts in Psychotherapy 17:211-216.

Roederer JG 1985 Neuropsychological processes relevant to the perception of music. An introduction. In: Spintge R, Droh R (eds) Music in Medicine, 61-86. Edition Roches, Basel.

Shine KI 2002 Health care quality and how to achieve it. Academic Medicine 77:91-99.
Spintge R, Droh R 1992 Music Medicine, Vol I. MMB Music Inc: Saint Louis.

StatSoft, Inc 2001 STATISTICA (data analysis software system), version 6. www.statsoft.com.

Surwit RS, Feinglos MN 1984 Relaxationinduced improvements in glucose tolerance is associated with decreased plasma cortisol. Diabetic Care 7:203-204.

Tanioka F, Takazawa T, Kamala S, Kudo M, Matsuki A, Oyama T 1985 Hormonal effect of anxiolytic music in patients during surgical operations under epidural anaesthesia. In: Spintge R, Droh R (eds) Music in Medicine, pp 285-290. Edition Roches, Basel.
Taylor DB 1999 Biomedical foundation of music as therapy, p 68. MMB Music, Inc., Saint Louis.

Thaut MH 2003 A scientific model of music in therapy and medicine. IMR Press, San Antonio.

Viljoen M 2003 Psychoneuroimmunology in terms of the two main stress areas. Sickness behaviour as a trigger for the development of mental disorders. PhD thesis, University of Pretoria.

Wensley D, Silverman M 2004 Peak flow monitoring for guided self-management in childhood asthma: a randomised controlled trial. American Journal of Respiratory and Critical Care Medicine Sep 15, 170(6):606-12. 


\section{Guidelines for Authors}

Contributions to the South African Journal of Physiotherapy are invited on any topic related to physiotherapy or rehabilitation. All articles that are submitted to the journal for publication must be accompanied by two questions with the correct answers.

\section{Types of Manuscripts}

1. Research

2. Case report

3. Clinical report

4. Technical report

5. Literature review

All manuscripts should be accompanied by a reference list.

\section{Legal Considerations}

Contributions will be considered for publication in the

South African Journal of Physiotherapy on condition that

- they have not been published previously.

- they have not been submitted for publication elsewhere.

- the Publications Division of the SASP reserves the copyright of all material published.

\section{Acceptance of manuscripts}

All manuscripts will be reviewed by two appointed referees. Identities of both authors and reviewers will be kept confidential in order to eliminate bias. Most articles require revision, in which case the reviewers' comments will be returned to the authors for consideration and alteration.

\section{Preparation and Presentation of Manuscripts}

\section{Articles}

1. Articles should be restricted to between 2000 and 2500 words.

2. Three copies submitted should be typewritten with double spacing and wide margins (a word-processing file, in WordPerfect 5.1, or Word 6.0 on a disk should be included).

3. A title page should be supplied as a separate sheet and include the name(s), qualifications and affiliation(s) of the author(s), together with addresses and telephone numbers (at home and at work).

4. Each article must be accompanied by an abstract of not more than 200 words. This should be on a separate sheet and should be intelligible without reference to the main text. Up to five key words should be included.

5. All abbreviations should be spelt out when first used.

6. The metric system is to be used throughout.

7. Headings must be presented in upper and lower case. Avoid using capitals only.

8. Authors must provide contact details; telephone numbers and email as well as postal address and institutional affiliation (hospital, University).

\section{Letters to the editor}

- if a letter is intended for the correspondence column it should be marked "for publication".

- it should be no longer than 400 words.

\section{References}

The accuracy and the completeness of references are of the utmost importance, and a maximum of 15 references per paper is required.

\section{References in the Text of the Article}

When referring to more than one paper, place the names of the principal authors in alphabetical order, eg Armstrong (1990), Jones (1988) and Smith and Jones (1990) refer to similar findings.

When there are two authors of a paper, mention both, eg Smith and Jones (1990), but when there are three or more, mention only the principal author and follow with et al, eg Thomas et al (1980).
When citing an author's work within a sentence in the main text of your article, follow these examples:

- Smith (1982) refers to the length of time taken for the subject to respond to a stimulus.

- Smith and Jones (1990) refer to similar findings.

- Smith (1982) and Thomas et al (1980) refer to problems in the method.

If quoting directly from another author, place the words in inverted commas and include the page number on which the quotation appears. For example: The clinical significance of increased tension or interruption of free movement in neural tissues is well recognised ..." (Yaxley and Jull 1990, p.143)

(Reference: Allison G (editor) 1997 Australian Journal of Physiotherapy Guidelines for Authors. In: Scientific Writers' Handbook. Australian Journal of Physiotherapy (publisher): 117)

\section{Reference list}

This should appear at the end of the paper in alphabetical order. The author's name should be followed by the initials (unpunctuated) and separated from the next author by a comma. The names of all the authors should be cited and et al should not be used in the reference list. Next should follow the date of publication and then the details of the publication.

a) Journal articles. Having stated the authors and the year of publication, the title of the article should be given in full. There should be a full stop after the title. This should be followed by the full title of the journal (abbreviations should not be used), then the volume number (not the part number) followed by a colon and then the first and last pages of the publication. The required format is illustrated in the following example: Erickson M, Upshur C 1989 Caretaking burden and social support: Comparison of mothers of infants with and without disabilities. American Journal of Mental Retardation 94:250-258

b) Books. The format as illustrated in the example should be followed. (Note the use of punctuation and capital letters ${ }^{1}$ ).

1) Payton OD 1994 Research: The validation of clinical practice, 3rd edn. ppl51-156. F.A. Davis Company, Philadelphia

2) Shephard KF 1993 Questionnaire design and use. In: Bork CE (ed) Research in Physical Therapy, ppl76-204. J.B. Lippincott Company, Philadelphia

\section{Illustrations}

- Tables and figures should be kept to a minimum and be on separate sheets.

- Each table should be numbered and have a clear title. Tables should not repeat material stated in the text. All tables and figures must be referenced in the text in sequential order.

- Don't send photographs as an integral part of a Word document. Send them separately as a Jpeg file.

- All illustrations should be clearly marked on the reverse side with arabic numerals, author's name and article, and an indication of the top side.

- All legends must be typed on a separate sheet.

- If a figure has been published before, the author must submit written permission from the copyright holder to reproduce the material.

\section{Manuscript submission}

- A covering letter, which must include the signature of each co-author, should accompany each manuscript.

- A word-processing file, in WordPerfect 5.1 or Word 6.0 should be included on a disk.

- Permission to reprint figures, extracts or abstracts from other publications should be included with the manuscript on submission. 